\title{
Adeno-Associated Virus Vector Expressing Nerve Growth Factor Enhances Cholinergic Axonal Sprouting after Cortical Injury in Rats
}

\author{
Julio J. Ramirez, ${ }^{1,2}$ Jennifer L. Caldwell, ${ }^{2}$ Melanie Majure, ${ }^{2}$ David R. Wessner, ${ }^{3}$ Ronald L. Klein, ${ }^{4}$ Edwin M. Meyer, ${ }^{4}$ and \\ Michael A. King, \\ ${ }^{1}$ Department of Psychology, ${ }^{2}$ Neuroscience Program, and ${ }^{3}$ Department of Biology, Davidson College, Davidson, North Carolina 28035, Departments of \\ ${ }^{4}$ Pharmacology and ${ }^{5}$ Neuroscience, University of Florida, Gainesville, Florida 32610, and ${ }^{6}$ Veterans Administration Medical Center, Gainesville, \\ Florida 32608
}

Nerve growth factor (NGF) is known to promote both the survival of cholinergic neurons after injury and the regeneration of damaged cholinergic axons. Recent evidence has implicated NGF in the regulation of cholinergic axonal sprouting by intact neurons projecting to the hippocampus of rats, sustaining a lesion of the entorhinal cortex. We explored the possibility that NGF may regulate this lesioninduced cholinergic sprouting by injecting recombinant adeno-associated virus (rAAV) vector expressing NGF and green fluorescent protein (GFP) into the dentate gyrus of rats that were subsequently given unilateral entorhinal lesions. Sprague Dawley rats were unilaterally injected with (1) rAAV vector expressing NGF and GFP or (2) rAAV vector expressing GFP. Fourteen days after injection, the animals received lesions of the entorhinal area ipsilateral to the virus injection. Four days after lesion, GFP expression and the septodentate sprouting response in the dentate gyrus were assessed. Optical densitometric analyses revealed a significant increase in acetylcholinesterase label (a marker for cholinergic septodentate sprouting) in the ipsilateral outer molecular layer of the dentate gyrus in rats injected with rAAV vector expressing NGF. Thus, NGF-expressing rAAV vector enhanced the sprouting response of intact cholinergic neurons after unilateral entorhinal lesions in rats.

Key words: acetylcholinesterase; dentate gyrus; entorhinal cortex; hippocampus; neuroplasticity; nerve growth factor; reactive synaptogenesis; sprouting; trophic factor

\section{Introduction}

Injury to the CNS of adult mammals may induce a dramatic reorganization of surviving neural circuitry. Axonal sprouting, an example of this reorganization, occurs widely throughout the adult CNS, including the cortex (Stroemer et al., 1993), the brainstem (Goodman and Horel, 1966), and the spinal cord (Liu and Chambers, 1958). The rat hippocampal formation is a particularly heuristic model preparation to study structural reorganization after cortical injury. Of the synapses found in the outer molecular layer of the dentate gyrus, $\sim 90 \%$ are of ipsilateral entorhinal origin (Steward and Vinsant, 1983). After a unilateral entorhinal cortex lesion in rats that results in a substantial deafferentation of the ipsilateral dentate gyrus, the cholinergic septodentate pathway and several other surviving afferents sprout within 1 week of cortical lesion (for review, see Ramirez, 2001). This lesion-induced sprouting is not limited to rats, because similar hippocampal sprouting responses occur in brains damaged by Alzheimer's disease (Geddes et al., 1985; Hyman et al., 1987).

Since the discovery of nerve growth factor (NGF), which has

\footnotetext{
Received Aug. 14, 2002; revised Jan. 24, 2003; accepted Jan. 24, 2003.

This work was supported by National Science Foundation Grant IBN9722829, National Institutes of Health (NIH) Grant MH-60608, and Howard Hughes Medical Institute Grant 71196-503202 (J.J.R.), NIH Grant NS-37432 (E.M.M.), and a grant from the Alzheimer's Association. We thank Charlotte White and Stephanie Courchesne for technica assistance.

Correspondence should be addressed to Dr. Julio J. Ramirez, Department of Psychology, Box 7017, Davidson College, Davidson, NC 28035-7017. E-mail: juramirez@davidson.edu.

Copyright $\odot 2003$ Society for Neuroscience $\quad$ 0270-6474/03/232797-07\$15.00/0
}

potent neuritogenic effects in sympathetic neurons (LeviMontalcini, 1987), neurotrophic factors in particular have been scrutinized as potential mechanisms regulating axonal sprouting after CNS injury. Indeed, within the partially denervated hippocampus, gene expression and/or immunocytochemical labeling for several neurotrophic factors increases during the first week after lesion; these factors include basic fibroblast growth factor (Gomez-Pinilla et al., 1992; Fagan et al., 1997), ciliary neurotrophic factor (Guthrie et al., 1997), insulin growth factor-1 (Guthrie et al., 1995), and NGF (Conner et al., 1994). Of these factors, NGF may be especially important in regulating lesioninduced septodentate sprouting. After an entorhinal lesion, NGF and NGF receptor (NGFR) immunoreactivity increases in the outer molecular layer of the dentate gyrus, the zone innervated by the AChE-containing cholinergic septodentate input (GomezPinilla et al., 1987; Conner et al., 1994). In fact, intraventricular infusion of antibody to NGF eliminates septodentate sprouting after entorhinal injury (Van der Zee et al., 1992). The possibility that NGF may regulate septodentate sprouting is tempered somewhat, however, by the observation that neither extractable NGF nor NGF mRNA levels in the denervated dentate are altered by entorhinal injury (Conner et al., 1994; Fagan et al., 1997). Moreover, because the polyclonal antibody to NGF may also target brain-derived neurotrophic factor and neurotrophin-3, these latter neurotrophins may have had a primary role in the regulation of septodentate sprouting (Van der Zee et al., 1992).

The objective of the present investigation was to determine 


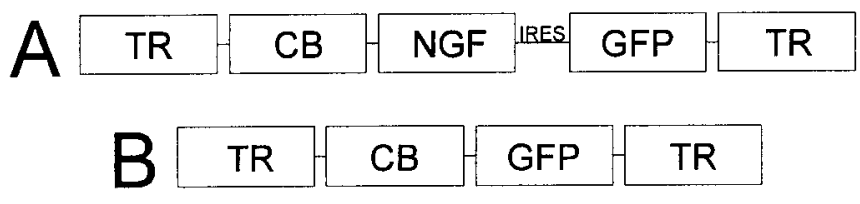

Figure 1. Recombinant virus vector was constructed from an adeno-associated virus. With the exception of the terminal repeats $(T R)$, all viral genes were removed, making the virus replication-defective, and were replaced with genes for NGF and/or GFP under the control of cytomegalovirus/chicken $\beta$-actin hybrid promoter (CB). A, pCB-NGF; B, pTR-UF12.1. IRES, Internal ribosome entry site.

whether NGF might control cholinergic sprouting induced by cortical injury. We injected recombinant adeno-associated virus (rAAV) vector, constructed to drive the expression of NGF and green fluorescent protein (GFP), into the dentate gyrus of rats that subsequently sustained unilateral entorhinal lesions. We hypothesize that if NGF is involved in the regulation of lesioninduced sprouting of the cholinergic septodentate input, transduction of dentate neurons with NGF-rAAV vector should enhance septodentate sprouting.

\section{Materials and Methods}

Subjects. Male Sprague Dawley rats (350-400 gm; Hilltop Breeders, Scotsdale, PA) were housed individually and maintained on a $12 \mathrm{hr}$ light/ dark cycle immediately after arrival in the laboratory. Food and water were available to the rats ad libitum throughout the experiment. The research reported here was approved by the Davidson College Institutional Animal Care and Use Committee and was conducted in accordance with the guidelines of the Animal Welfare Act and the National Institutes of Health.

Research design. The rats were randomly assigned to one of four treatment conditions, as follows: (1) sham/rAAV vector expressing GFP (12.1-S; $n=5)$; (2) sham/rAAV vector expressing NGF and GFP (NGF-S; $n=6$ ); (3) unilateral entorhinal lesion/rAAV vector expressing GFP (12.1-L; $n=6)$; and (4) unilateral entorhinal lesion/rAAV vector expressing NGF and GFP (NGF-L; $n=6$ ). To ensure effective expression of vector products, the rAAV vector was injected into the dentate gyrus 2 weeks before the ipsilateral entorhinal lesion. A postlesion survival interval of $4 \mathrm{~d}$ was chosen because this is the time point at which lesioninduced septodentate sprouting is just beginning (Fass and Ramirez, 1984). Therefore, we were able to detect whether the rAAV vector-driven NGF expression hastened the onset of septodentate sprouting.

Vector preparation. Nerve growth factor was delivered to the dorsal dentate gyrus with an rAAV vector. The rAAV vector has been shown to deliver genetic material directly to neurons in the CNS in a localized nontoxic manner, with chronic synthesis over the time span we investigated (Kaplitt et al., 1994; Xiao et al., 1997; Klein et al., 1999). The rAAV vectors used in this investigation were obtained from the Vector Core Laboratory at the University of Florida (Gainesville, FL), and their preparation has been described in detail elsewhere (Klein et al., 2002). Briefly, the recombinant virus vector was constructed from an AAV that was rendered replication-defective. With the exception of the terminal repeats, the viral genes were removed and replaced with genes for NGFmyc and/or GFP under the control of a cytomegalovirus/chicken $\beta$-actin hybrid promoter (Fig. 1). The plasmid contained AAV terminal repeats that flanked the expression cassettes of pTR-UF12.1 or pCB-NGFmyc. Green fluorescent protein served as the reporter gene to identify cellular transduction within the targeted regions. Tyrosine kinase A (TrkA) autophosphorylation and neurite outgrowth assays from PC12 cell cultures had confirmed previously the full efficacy of the myc-tagged NGF (Moller et al., 1998). The constructs derived from pTR-UF12.1 contain the internal ribosome entry site from poliovirus (Dirks et al., 1993) providing the bicistronic expression of NGFmyc and an enhanced form of GFP (Klein et al., 1998).

Surgical preparation. Immediately before surgery under aseptic conditions, the rats were given an injection of $0.1 \mathrm{ml}$, i.p., of atropine sulfate and anesthetized with an injection of sodium pentobarbital (Nembutal, $50 \mathrm{mg} / \mathrm{kg}$, i.p.). Two microliters of rAAV vector [either the pCBNGFmyc (infectious titer, $1.7 \times 10^{10} / \mathrm{ml}$ ) or the pTR-UF12.1 (infectious titer, $\left.1.4 \times 10^{11} / \mathrm{ml}\right)$ ] were unilaterally injected at a rate of $0.1 \mu \mathrm{l} / \mathrm{min}$ for 20 min into the right dorsal dentate gyrus (incisor bar set at $+5.0 \mathrm{~mm} ; 2.0$ posterior to bregma, 1.5 lateral to sagittal sinus, 3.0 ventral to dura).

As previously described (Loesche and Steward, 1977), unilateral entorhinal lesions in the right hemisphere (i.e., ipsilateral to the rAAV injection) were made by lowering a stainless steel, insulated (except at the tip) electrode to the following stereotaxic coordinates: incisor bar set at -2.0 $\mathrm{mm}, 1.5 \mathrm{~mm}$ anterior to the transverse sinus; 3,4 , and $5 \mathrm{~mm}$ lateral to the sagittal sinus; and 2, 4, and $6 \mathrm{~mm}$ ventral to dura. A $1.0 \mathrm{~mA}$ current was passed through the electrode for a period of $45 \mathrm{sec}$ at each coordinate (Ramirez and Stein, 1984). Animals that received sham surgery were treated similarly, with the exception of the penetration of the electrode into the brain (note that all animals received rAAV vector injection).

Histology. Four days after lesion, the rats were killed with Nembutal $(100 \mathrm{mg} / \mathrm{kg}$ ) and perfused transcardially with $100 \mathrm{ml}$ PBS chased by 400 $\mathrm{ml}$ of $10 \%$ buffered formalin. After post-fixing in 30\% sucrose formalin for a minimum of $3 \mathrm{~d}$, the brains were blocked; the anterodorsal hippocampal formation was sectioned coronally, whereas the posteroventral hippocampal formation was sectioned horizontally. The $30-\mu \mathrm{m}$-thick sections were examined for evidence of GFP fluorescence using a fluorescein isothiocyanate long-pass filter. Coronal sections within $30 \mu \mathrm{m}$ of fluorescing sections and every third section through the ventral hippocampal formation were stained for AChE-containing fibers with Naik's AChE histochemical technique (Naik, 1963) (using promethazine as an inhibitor of nonspecific cholinesterase) (cf. Lynch et al., 1972) to label sprouting by the AChE-containing, cholinergic septodentate pathway (Fass and Ramirez, 1984). The AChE label is localized primarily to terminals and axons (Shute and Lewis, 1966; Cotman et al., 1973) and is taken as evidence of the AChE-containing septodentate pathway (Steward, 1992) (for review, see Ramirez, 2001). Lesion assessments were performed on tissue stained with cresyl violet acetate to determine the extent of injury in the vicinity of the injection site and to confirm that the electrolytic lesions were localized to the medial and lateral aspects of the entorhinal area.

Optical densitometry. The density of the AChE label in the dentate gyrus was determined with the BioQuant Nova image analysis system (Bioquant Image Analysis, Nashville, TN). Density measurements were taken at the outer molecular layer (OML), the inner molecular layer (IML), and the supragranular zone (SGZ) of the dentate gyrus ipsilateral and contralateral to the entorhinal lesion (Fig. 2). In addition, density measurements were taken from adjacent sections of the dorsal hippocampus $30 \mu \mathrm{m}$ away from sections evidencing the greatest GFP expression to ensure that only areas in which the rAAV vector is likely to have driven the expression of NGF were assessed. All dorsal density measurements were $\sim 500 \mu \mathrm{m}$ lateral to the injection location. Horizontal, ventral hippocampal sections were analyzed at $-5.10 \mathrm{~mm}$ below bregma (Paxinos and Watson, 1986). To control for staining variability between sections, the inner molecular layer of the dentate gyrus of each section assessed was used as the control for background. The IML is a palestaining zone not known to undergo lesion-induced increases in septodentate innervation (Stanfield and Cowan, 1982). The optical density measurements were expressed as the ratio $Z=X / Y$, where $X=$ ipsilateral OML - ipsilateral IML and $Y=$ contralateral OML - contralateral IML. Because the perforant path projection is almost exclusively ipsilateral, the contralateral dentate gyrus may serve as a within-animal control (Steward and Vinsant, 1983). Creating a ratio of ipsilateral to contralateral measurements provides an excellent within-section control for random variability in AChE staining (Fass and Ramirez, 1984; Steward, 1992). Therefore, a value of 1.0 indicates equivalent density measurements between sides, whereas a value $>1.0$ indicates greater staining ipsilateral to the lesion and a value $<1.0$ indicates greater staining contralateral to the lesion. Because there is a possibility that the rAAV-NGF vector may nonspecifically increase the levels of AChE in the septodentate pathway, we performed optical densitometric studies of the supragranular zone (a region that is innervated by the septodentate pathway but has not been shown to sprout in response to an entorhinal lesion) (Stanfield and 


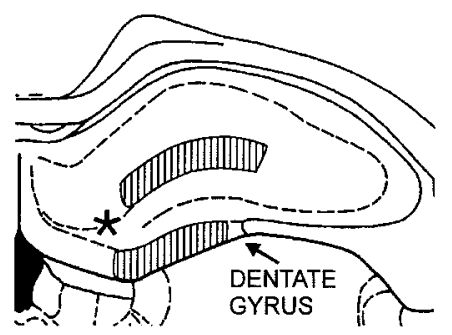

\section{DORSAL HIPPOCAMPAL FORMATION}

\section{VENTRAL HIPPOCAMPAL FORMATION}

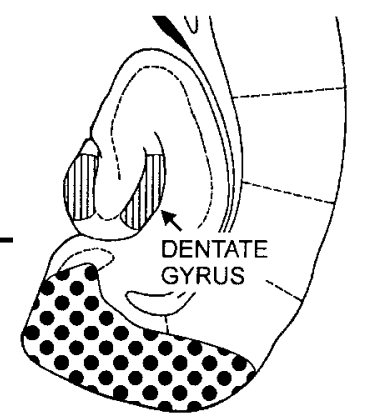

Figure 2. Optical density measurements were taken from the dentate gyrus. The dorsal coronal section was matched to the area expressing GFP. The outer molecular layer and supragranular zone of the dentate gyrus were sampled from the adjacent $30 \mu \mathrm{m}$ section. [Figure modified from Paxinos and Watson (1986); the striped area indicates the sampled dentate gyrus; the stippled area indicates the typical extent of an entorhinal lesion; the asterisk $\left(^{*}\right)$ indicates the approximate location of the cell illustrated in Figure 3.]

Cowan, 1982). The algorithm we used for the supragranular zone analysis was identical to that described above, with the exception that we substituted the supragranular zone density for the outer molecular layer density. The experimenters conducting the optical densitometric assessments were blind to the treatment condition of the cases.

\section{Results}

\section{Lesion assessment and GFP expression}

The assessment of the entorhinal lesions confirmed that the extent of the lesions was comparable between the lesioned groups (Fig. 2 illustrates the typical lesion). Both medial and lateral aspects of the entorhinal area were injured in all the rats sustaining entorhinal lesions. Parasubiculum and presubiculum were injured to a variable extent in all animals. The dentate gyrus was free of injury in all cases.

Visual inspection of the dorsal and ventral sections indicated that the GFP expression for both the pCB-NGF and pTR-UF12.1 was restricted principally to the site of the injection, most often at the interface between the dentate hilus and the granule cell layer. Occasionally, cells were so well labeled that the morphology was clearly indicative of a neuronal cell type (Fig. 3), although the precise identity of the cell could not be determined.

\section{Optical densitometry}

An omnibus $F$ test $(2 \times 2 \times 2$ ANOVAs: lesion $\times$ vector $\times$ hippocampal level) was performed on the optical density ratios derived from the OML and SGZ (Systat; SPSS, Chicago, IL). Because of the large number of comparisons, we performed conservative Scheffé post hoc contrasts to control for familywise type I error (Keppel and Zedeck, 1989).

The dorsal hippocampus of rats sustaining entorhinal injury and pCB-NGF transduction exhibited significantly higher optical density ratios than all the other groups at the level of the dorsal hippocampus and all comparisons at the ventral hippocampus

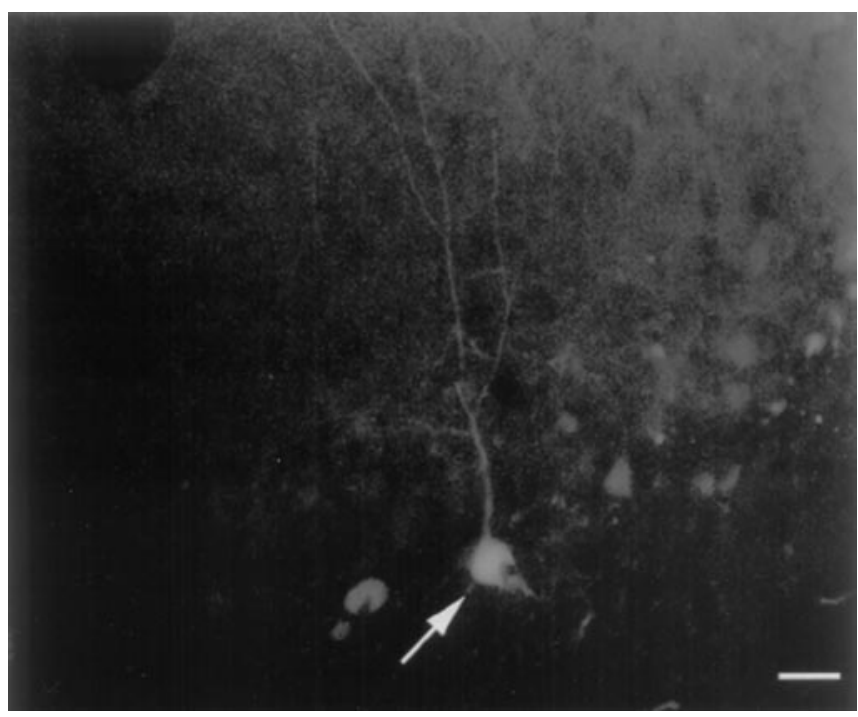

Figure 3. GFP fluorescence was detected in the cells in the granule cell layer/hilar region of the dorsal dentate gyrus ipsilateral to the injection of rAAV driving the expression of GFP. Note the fluorescing cell (white arrow). Unstained sections were analyzed for fluorescence using a fluorescein isothiocyanate long-pass filter. Scale bar, $30 \mu \mathrm{m}$.

(Figs. 4, 5) (Scheffé post hoc contrasts indicated values of $p \leq$ $0.001)$. The analysis of the optical density ratios for the outer molecular layer indicated significant main effects for lesion $\left(F_{(1,38)}=7.95, p<0.01\right)$, vector $\left(F_{(1,38)}=6.25, p<0.02\right)$, and level $\left(F_{(1,38)}=9.25, p<0.005\right)$; significant interactions for lesion $\times \operatorname{vector}\left(F_{(1,38)}=10.06, p<0.005\right)$, lesion $\times \operatorname{level}\left(F_{(1,38)}=\right.$ $8.46, p<0.01)$, and vector $\times$ level $\left(F_{(1,38}=9.21, p<0.005\right)$; and a significant three-way interaction for lesion $X$ vector $\times$ level $\left(F_{(1,38)}=7.03, p<0.015\right)$. The rats sustaining entorhinal injury with pTR-UF12.1 transduction in the dorsal hippocampus did not exhibit elevated optical density ratios relative to the ventral hippocampus. Indeed, as Figure $4 A$ indicates, with the exception of the dorsal hippocampus of rats transduced with pCB-NGF, the optical density ratios of all of the groups approximated 1.0, indicating equivalent OML densities ipsilateral and contralateral to the operated side. The analysis of the SGZ ratios indicated that neither the lesions nor the vector treatments significantly affected the optical density ratios, which approximated 1.0 (Fig. 4B). Although we observed a significant lesion $\times$ level interaction $\left(F_{(1,38)}=11.84, p<0.05\right)$, subsequent Scheffé post hoc contrasts indicated that the groups were not significantly different from one another (Scheffé $p$ values $>0.05$; lesion $\times$ vector $\times$ level: $\left.F_{(1,38)}=1.63, p>0.20\right)$.

\section{Discussion}

As revealed in the optical density analysis of AChE label, transducing cells in the dorsal hippocampus with rAAV vector constructed to drive the expression of NGF enhanced the sprouting response of the cholinergic septodentate pathway after unilateral entorhinal lesions in rats. The observed enhanced onset of cholinergic septodentate sprouting in the rAAV-NGF transduced animals occurs at a time point when the normal sprouting response is just beginning (i.e., $\sim 4 \mathrm{~d}$ after lesion). Whereas the rAAV vector expressing NGF enhanced the septodentate sprouting response in the dorsal hippocampus (the site of the vector injection), the vector did not substantially affect the sprouting response in the ventral hippocampus (a site removed from the injection). The effects of the vector, therefore, seem to be localized to the immediate location of the injection and transduction. 


\section{A}

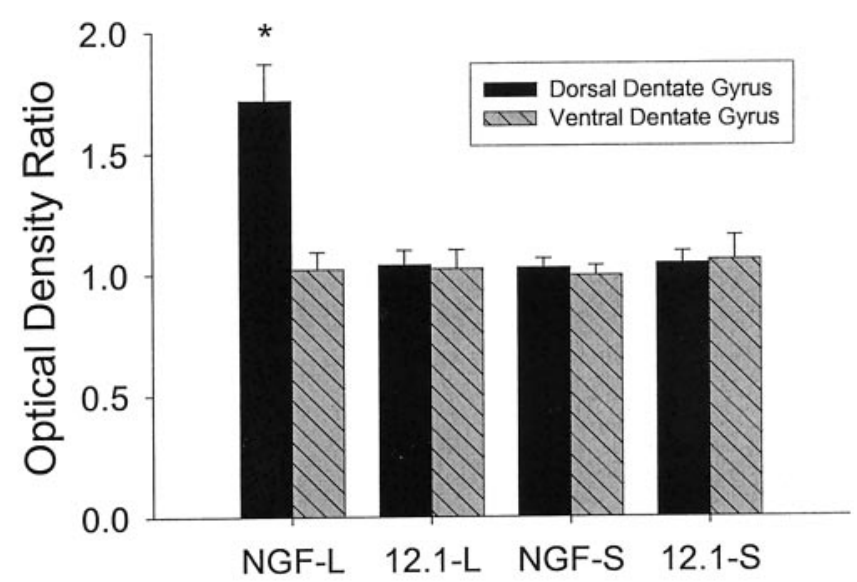

B

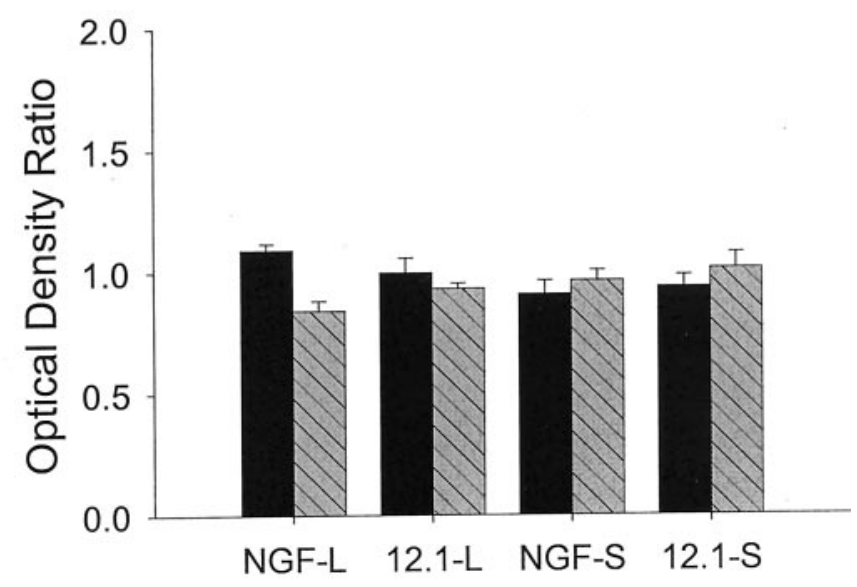

Figure 4. Optical density (ipsilateral/contralateral ratios) observed in the outer molecular layer $(A)$ or supragranular zone $(B)$ after unilateral entorhinal lesions or sham operations and treatment with rAAV expressing NGF and/or GFP at $4 \mathrm{~d}$ after lesion. $A$, 0 nly the outer molecular layer of the dorsal dentate gyrus of the lesioned group treated with rAAV expressing NGF and GFP (NGF-L) demonstrated a significant elevation in the optical density ratio that differed significantly from all other groups $\left({ }^{*} p \leq 0.001\right)$. No statistically significant differences were observed among the other groups [i.e., the 12.1-rAAV-treated lesioned group (12.1-L), the NGFrAAV-treated sham-operates (NGF-S), and the 12.1-rAAV-treated sham-operates (12.1-S)]. B, All of the values approximated 1.0, indicating relatively equivalent levels of $A C h E$ label in the supragranular zone ipsilateral and contralateral to the entorhinal lesion. No statistically significant differences were observed among the groups.

Despite a robust septodentate sprouting response in the molecular layer of rats injected with the rAAV vector expressing NGF, the supragranular zone did not evidence an elevated staining intensity. Thus, the increased staining of the septodentate pathway is limited to the component of the projection undergoing terminal proliferation.

Before discussing the significance of our findings, we need to address two methodological issues potentially affecting our interpretations, as follows: (1) the validity of the AChE histochemical technique to identify cholinergic septodentate sprouting and (2) the contribution that shrinkage may make to the values reported here. Conceivably, the increase in label observed in the outer molecular layer may have been a consequence of nonspecific in- creases in AChE synthesis resulting in greater AChE per terminal, although the number of terminals remained unchanged. On the contrary, studies relying on autoradiographic (Stanfield and Cowan, 1982) or Phaseolus vulgaris leucoagglutinin (Nyakas et al., 1988) anterograde tract tracing techniques demonstrated morphologically a dramatic proliferation of the septodentate pathway that was in register with the proliferated AChE-labeled pathway in the OML. Indeed, our observation that the increases in AChE label are restricted to the OML terminal field undergoing proliferation and not in the adjacent SGZ terminal field underscores the proposal that the rAAV vector did not produce a generic elevation in AChE label in the target region. One might also reasonably question whether the AChE label is a valid marker for the cholinergic nature of the septodentate pathway (Aubert et al., 1994). Naumann et al. (1997) recently demonstrated that the selective destruction of cholinergic septal neurons with 192 IgGsaporin (a neurotoxin that selectively destroys cholinergic neurons in the basal forebrain) (Heckers et al., 1994) eliminated the AChE-containing septodentate pathway that normally sprouts after an entorhinal lesion. Finally, the possibility exists that increases in OML density may be an artifact of shrinkage, because there is such a massive denervation after a unilateral entorhinal lesion. Shrinkage of the molecular layer $4 \mathrm{~d}$ after lesion, however, is on the order of 5\% (Lynch et al., 1975; Ramirez et al., 1999). In contrast, the mean optical density ratio of the rats transduced with rAAV-NGF evidenced an increase of $72 \%$. Shrinkage alone is therefore an unlikely explanation of the increases we report here.

Our results demonstrate that NGF may be a signal event in the remodeling of the dentate architecture after an entorhinal injury. Many trophic factors increase in denervated molecular layer after an entorhinal cortex lesion, and it is likely that an intricate interplay of these substances results in the initiation, guidance, and final arrangement of the circuitry surviving the injury. Nonetheless, NGF is clearly a significant component in the hippocampal response to cortical deafferentation, if we look at our results together with the observations that anti-NGF inhibits lesioninduced septodentate sprouting (Van der Zee et al., 1992) and that the NGF receptor and immunolabeling both increase within the first week after an entorhinal injury (Gomez-Pinilla et al., 1987; Conner et al., 1994). Exogenous administration of NGF has been shown to promote sprouting by damaged axons of the septohippocampal pathway after fimbria-fornix transection in adult animals (for review, see Gage et al., 1990). Our findings extend these observations by demonstrating that in adult animals, NGF may orchestrate the growth of undamaged fibers undergoing axonal sprouting in response to cortical injury. Indeed, NGF may play a similar role in the axonal sprouting that occurs in other cortical regions, for example, in the visual cortex after retinal lesions. Increases in several neurotrophins, including NGF, accompany the axonal sprouting known to occur in the cortical area deprived of visual inputs (Darian-Smith and Gilbert, 1994; Obata et al., 1999), perhaps through the modulation of extant cholinergic inputs (Berardi et al., 1994; Rossi et al., 2002).

An interesting feature of the cholinergic sprouting response reported here is that despite the potential for an ectopic pattern of dentate innervation in the rAAV-NGF-transduced rats, the septodentate pathway maintained its normal laminar pattern of OML innervation. The cells transduced in the present investigation often were in the vicinity of the hilar/granule cell layer interface (Fig. 3). Despite this location, apparently, the intrinsic mechanism(s) that regulates the anatomic profile of the dentate gyrus continues to operate in a system that has been transduced with 

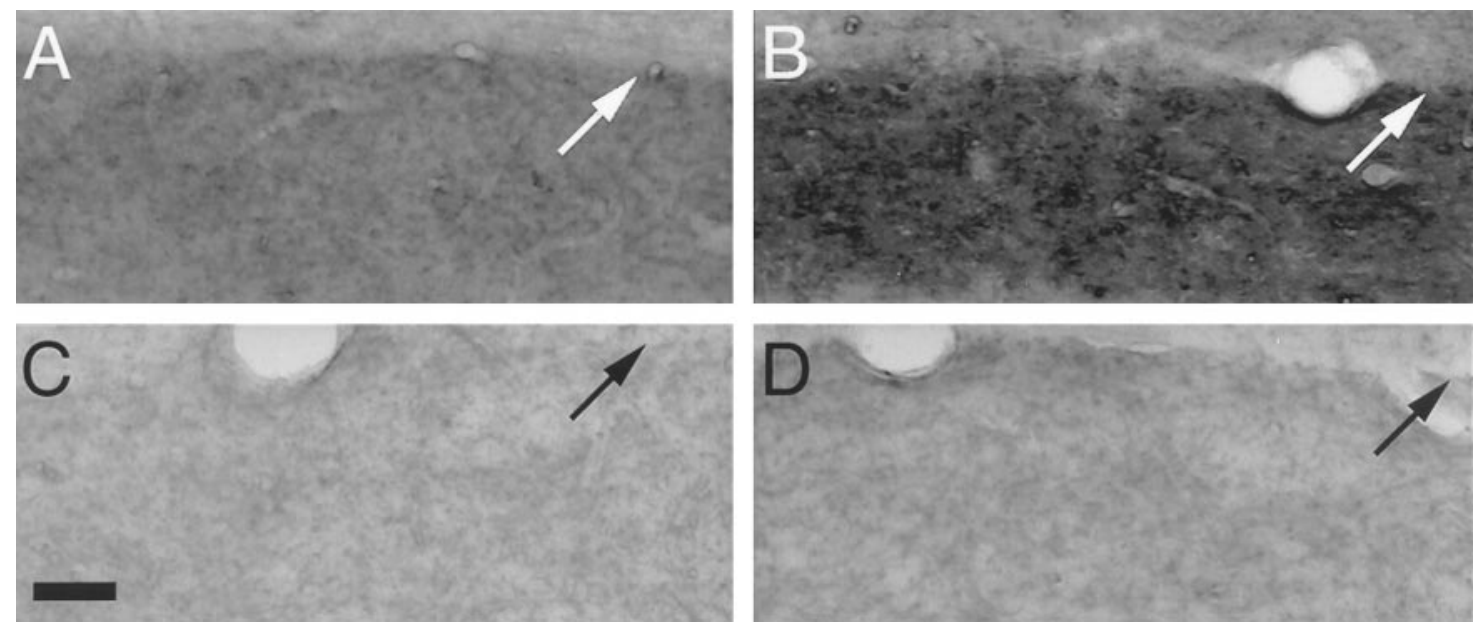

Figure 5. At $4 \mathrm{~d}$ after lesion, relative to the OML of a lesioned rat with rAAV expressing GFP alone $(A)$, the sprouting response of the AChE-containing septal input to the dorsal dentate gyrus is greatest in the OML ipsilateral to the entorhinal lesion in a rat with rAAV expressing NGF and GFP ( $B$ ). Note the similarity in staining intensity of the ipsilateral OML in the sham-operated rat with rAAV expressing GFP alone (C) and in the sham-operated rat with rAAV expressing NGF and GFP (D).C, Scale bar, $50 \mu \mathrm{m}$; small white or black arrow indicates the outer limit of the dentate molecular layer.

rAAV-NGF. Precisely which mechanism(s) may be involved cannot be determined from our findings, but plausible contributors to this architectonic regulation include extracellular matrix proteins (Deller et al., 2001) and the capture and anchoring of newly released NGF in the OML (Conner et al., 1994). It is of interest to note that although the implantation of transfected fibroblasts expressing NGF into the basal forebrain of monkeys reversed the loss of age-related cholinergic cells, the fibroblasts also produced extensive ectopic sprouting of p75-labeled cholinergic neurons into the graft (Smith et al., 1999).

The mechanism by which the rAAV-NGF-transduced cells increase cholinergic septodentate sprouting probably involves the NGFR located in the denervated dentate gyrus. The postsynaptic receptors by which NGF exerts neurotrophic effects include the high-affinity receptor tyrosine kinase A (TrkA) and the lowaffinity p75 receptor (for review, see Sofroniew et al., 2001). The p75 receptor is distributed throughout the dentate in a pattern resembling the AChE-containing septodentate input (Peterson et al., 1994). In addition, the $\mathrm{p} 75$ and the TrkA receptors are distributed in the dentate similarly to the septal input (Sobreviela et al., 1994; Dougherty and Milner, 1999; Barker-Gibb et al., 2001). The colocalization of p75 and TrkA in the septal fibers may be an important property dictating the probability of high-affinity binding (Hempstead et al., 1991; Esposito et al., 2001) and the consequent proliferation of cholinergic synapses.

The role of NGF in the regulation of lesion-induced sprouting notwithstanding, it is evident from the intact cases that transducing the dentate cells with the rAAV-NGF did not alter the normal septodentate projection to the OML. Thus, the initiation of a septodentate growth response seems to rely on factors additional to the NGF. After an entorhinal lesion, a cascade of cellular events is instigated, including the degeneration of neuronal elements (Steward, 1992; Shi and Stanfield, 1996; Jensen et al., 1999), microglial and astrocytic activation (Jensen et al., 1994), and the increased synthesis of extracellular matrix proteins (Deller et al., 2001). In this context, the degeneration of presynaptic elements may be particularly salient for the induction of sprouting, as suggested by studies indicating that a delay in the onset of Wallerian degeneration after a perforant path lesion produces a parallel delay in the onset of septodentate sprouting (Steward, 1992; Shi and Stanfield, 1996).

Finally, our results demonstrate that using rAAV vector to deliver NGF directly into the parenchyma is efficacious and may be used to promote the reorganization of neural circuitry. Intraventricular infusion of NGF into the brain-injured or aged rat has been shown to promote regeneration or to reverse age-related atrophy of cholinergic neurons (for review, see Sofroniew et al., 2001). Unfortunately, use of either systemic or intraventricular infusion as a clinical tool may be limited by complications such as hypophagia and weight loss (Williams, 1991) and hyperalgesia (for review, see Shu and Mendell, 1999). Moreover, intraventricular infusion of NGF may result in poor diffusion out to the parenchyma (Fischer et al., 1994), and it is becoming clear that precise delivery may be critical for effective and controlled neural outcomes (Mahoney and Saltzman, 1999). Gene therapy involving the neurotrophic properties of NGF has been used successfully to promote the survival of subcortical cholinergic neurons in rat (Martinez-Serrano and Bjorklund, 1998) and monkey (Smith et al., 1999). In addition to the latter possible neurotrophic effects, we now show that NGF driven by pCB-rAAV vector construct is also capable of exerting neurotropic (i.e., neuritepromoting) effects, resulting in the proper establishment of cholinergic circuitry in the adult mammalian brain. Given the discovery of cholinergic axonal sprouting in the hippocampus of patients with Alzheimer's disease (Geddes et al., 1985; Hyman et al., 1987), future studies exploring the functional significance of this cholinergic sprouting using gene delivery technologies similar to those used here may be well worth pursuing. Indeed, although the behavioral consequences of hippocampal reorganization are unclear in human beings, hippocampal sprouting of glutamatergic pathways in rats after unilateral entorhinal lesions has been shown to be beneficial in tests of mnemonic function (Loesche and Steward, 1977; Reeves and Smith, 1987; Ramirez et al., 1996).

\section{References}

Aubert I, Poirier J, Gauthier S, Quirion R (1994) Multiple cholinergic markers are unexpectedly not altered in the rat dentate gyrus following entorhinal cortex lesions. J Neurosci 14:2476-2484.

Barker-Gibb AL, Dougherty KD, Einheber S, Drake CT, Milner TA (2001) Hippocampal tyrosine kinase A receptors are restricted primarily to presynaptic vesicle clusters. J Comp Neurol 430:182-199.

Berardi N, Cellerino A, Domenici L, Fagiolini M, Pizzorusso T, Cattaneo A, Maffei L (1994) Monoclonal antibodies to nerve growth factor affect the 
postnatal development of the visual system. Proc Natl Acad Sci USA 91:684-688.

Conner JM, Fass-Holmes B, Varon S (1994) Changes in nerve growth factor immunoreactivity following entorhinal cortex lesions: possible molecular mechanism regulating cholinergic sprouting. J Comp Neurol 345:409-418.

Cotman CW, Matthews DA, Taylor D, Lynch G (1973) Synaptic rearrangement in the dentate gyrus: histochemical evidence of adjustments after lesions in immature and adult rats. Proc Natl Acad Sci USA 70:3473-3477.

Darian-Smith C, Gilbert CD (1994) Axonal sprouting accompanies functional reorganization in adult cat striate cortex. Nature 368:737-740.

Deller T, Haas CA, Frotscher M (2001) Sprouting in the hippocampus after entorhinal cortex lesion is layer-specific but not translaminar: which molecules may be involved? Restor Neurol Neurosci 19:159-167.

Dirks W, Wirth M, Hauser H (1993) Dicistronic transcription units for gene expression in mammalian cells. Gene 128:247-249.

Dougherty KD, Milner TA (1999) p75NTR immunoreactivity in the rat dentate gyrus is mostly within presynaptic profiles but is also found in some astrocytic and postsynaptic profiles. J Comp Neurol 407:77-91.

Esposito D, Patel P, Stephens RM, Perez P, Chao MV, Kaplan DR, Hempstead BL (2001) The cytoplasmic and transmembrane domains of the p75 and Trk A receptors regulate high affinity binding to nerve growth factor. J Biol Chem 276:32687-32695.

Fagan AM, Suhr ST, Lucidi-Phillipi CA, Peterson DA, Holtzman DM, Gage FH (1997) Endogenous FGF-2 is important for cholinergic sprouting in the denervated hippocampus. J Neurosci 17:2499-2511.

Fass B, Ramirez JJ (1984) Effects of ganglioside treatments on lesioninduced behavioral impairments and sprouting in the CNS. J Neurosci Res 12:445-458.

Fischer W, Sirevaag A, Wiegand SJ, Lindsay RM, Bjorklund A (1994) Reversal of spatial memory impairments in aged rats by nerve growth factor and neurotrophins 3 and 4/5 but not by brain-derived neurotrophic factor. Proc Natl Acad Sci USA 91:8607-8611.

Gage FH, Buzsaki G, Armstrong DM (1990) NGF-dependent sprouting and regeneration in the hippocampus. Prog Brain Res 83:357-370.

Geddes JW, Monaghan DT, Cotman CW, Lott IT, Kim RC, Chui HC (1985) Plasticity of hippocampal circuitry in Alzheimer's disease. Science 230:1179-1181.

Gomez-Pinilla F, Cotman CW, Nieto-Sampedro M (1987) NGF receptor immunoreactivity in rat brain: topographic distribution and response to entorhinal ablation. Neurosci Lett 82:260-266.

Gomez-Pinilla F, Lee JW, Cotman CW (1992) Basic FGF in adult rat brain: cellular distribution and response to entorhinal lesion and fimbria-fornix transection. J Neurosci 12:345-355.

Goodman DC, Horel JA (1966) Sprouting of optic tract projections in the brain stem of the rat. J Comp Neurol 127:71-88.

Guthrie KM, Nguyen T, Gall CM (1995) Insulin-like growth factor-1 mRNA is increased in deafferented hippocampus: spatiotemporal correspondence of a trophic event with axon sprouting. J Comp Neurol 352:147-160.

Guthrie KM, Woods AG, Nguyen T, Gall CM (1997) Astroglial ciliary neurotrophic factor mRNA expression is increased in fields of axonal sprouting in deafferented hippocampus. J Comp Neurol 386:137-148.

Heckers S, Ohtake T, Wiley RG, Lappi DA, Geula C, Mesulam MM (1994) Complete and selective cholinergic denervation of rat neocortex and hippocampus but not amygdala by an immunotoxin against the p75 NGF receptor. J Neurosci 14:1271-1289.

Hempstead BL, Martin-Zanca D, Kaplan DR, Parada LF, Chao MV (1991) High-affinity NGF binding requires coexpression of the trk protooncogene and the low-affinity NGF receptor. Nature 350:678-683.

Hyman BT, Kromer LJ, Van Hoesen GW (1987) Reinnervation of the hippocampal perforant pathway zone in Alzheimer's disease. Ann Neurol 21:259-267.

Jensen MB, Gonzalez B, Castellano B, Zimmer J (1994) Microglial and astroglial reactions to anterograde axonal degeneration: a histochemical and immunocytochemical study of the adult rat fascia dentata after entorhinal perforant path lesions. Exp Brain Res 98:245-260.

Jensen MB, Hegelund IV, Poulsen FR, Owens T, Zimmer J, Finsen B (1999) Microglial reactivity correlates to the density and the myelination of the anterogradely degenerating axons and terminals following perforant path denervation of the mouse fascia dentata. Neuroscience 93:507-518.

Kaplitt MG, Leone P, Samulski RJ, Xiao X, Pfaff DW, O’Malley KL, During MJ (1994) Long-term gene expression and phenotypic correction using adenoassociated virus vectors in the mammalian brain. Nat Genet 8:148-154

Keppel G, Zedeck S (1989) Data analysis for research designs: analysis of variance and multiple regression/correlation approaches, pp 173-174. New York: Freeman.

Klein RL, Meyer EM, Peel AL, Zolotukhin S, Meyers C, Muzyczka N, King MA (1998) Neuron-specific transduction in the rat septohippocampal or nigrostriatal pathway by recombinant adeno-associated virus vectors. Exp Neurol 150:183-194.

Klein RL, Muir D, King MA, Peel AL, Zolotukhin S, Moller JC, Kruttgen A, Heymach JV, Muzyczka N, Meyer EM (1999) Long-term actions of vector-derived nerve growth factor or brain-derived neurotrophic factor on choline acetyltransferase and Trk receptor levels in the adult rat basal forebrain. Neuroscience 90:815-821.

Klein RL, King MA, Hamby ME, Meyer EM (2002) Dopaminergic cell loss induced by human $\mathrm{A} 30 \mathrm{P}$ alpha-synuclein gene transfer to the rat substantia nigra. Hum Gene Ther 13:605-612.

Levi-Montalcini R (1987) The nerve growth factor 35 years later. Science 237:1154-1162.

Liu CM, Chambers WW (1958) Intraspinal sprouting of dorsal root axons. Arch Neurol Psychiat 79:46-61.

Loesche J, Steward O (1977) Behavioral correlates of denervation and reinnervation of the hippocampal formation of the rat: recovery of alternation performance following unilateral entorhinal cortex lesions. Brain Res Bull 2:31-39.

Lynch G, Matthews DA, Mosko S, Parks T, Cotman C (1972) Induced acetylcholinesterase-rich layer in rat dentate gyrus following entorhinal lesions. Brain Res 42:311-318.

Lynch G, Rose G, Gall C, Cotman CW (1975) The response of the dentate gyrus to partial deafferentation. In: Golgi centennial symposium proceedings (Santini M, ed), pp 305-317. New York: Raven.

Mahoney MJ, Saltzman WM (1999) Millimeter-scale positioning of a nerve-growth-factor source and biological activity in the brain. Proc Natl Acad Sci USA 96:4536-4539.

Martinez-Serrano A, Bjorklund A (1998) Ex vivo nerve growth factor gene transfer to the basal forebrain in presymptomatic middle-aged rats prevents the development of cholinergic neuron atrophy and cognitive impairment during aging. Proc Natl Acad Sci USA 95:1858-1863.

Moller JC, Kruttgen A, Heymach Jr JV, Ghori N, Shooter EM (1998) Subcellular localization of epitope-tagged neurotrophins in neuroendocrine cells. J Neurosci Res 51:463-472.

Naik NT (1963) Technical variations in Koelle's histochemical method for demonstrating cholinesterase activity. Q J Microsc Methods 104:89-100.

Naumann T, Deller T, Bender R, Frotscher M (1997) 192 IgG-saporininduced loss of cholinergic neurons in the septum abolishes cholinergic sprouting after unilateral entorhinal lesion in the rat. Eur J Neurosci 9:1304-1313

Nyakas C, Luiten PG, Balkan B, Spencer Jr DG (1988) Changes in septohippocampal projections after lateral entorhinal or combined entorhinalraphe lesions as studied by anterograde tracing methods. Brain Res Bull 21:285-293.

Obata S, Obata J, Das A, Gilbert CD (1999) Molecular correlates of topographic reorganization in primary visual cortex following retinal lesions. Cereb Cortex 9:238-248.

Paxinos G, Watson C (1986) The rat brain in stereotaxic coordinates. New York: Academic.

Peterson GM, Ginn SR, Lanford GW (1994) Fibers immunoreactive for nerve growth factor receptor in adult rat cortex and hippocampus mimic the innervation pattern of AChE-positive fibers. Brain Res Bull 33:129-136.

Ramirez JJ (2001) The role of axonal sprouting in functional reorganization after CNS injury: lessons from the hippocampal formation. Restor Neurol Neurosci 19:237-262.

Ramirez JJ, Stein DG (1984) Sparing and recovery of spatial alternation performance after entorhinal cortex lesions in rats. Behav Brain Res 13:53-61.

Ramirez JJ, McQuilkin M, Carrigan T, MacDonald K, Kelley MS (1996) Progressive entorhinal cortex lesions accelerate hippocampal sprouting and spare spatial memory in rats. Proc Natl Acad Sci USA 93:15512-15517.

Ramirez JJ, Finklestein SP, Keller J, Abrams W, George MN, Parakh T (1999) Basic fibroblast growth factor enhances axonal sprouting after cortical injury in rats. NeuroReport 10:1201-1204. 
Reeves TM, Smith DC (1987) Reinnervation of the dentate gyrus and recovery of alternation behavior following entorhinal cortex lesions. Behav Neurosci 101:179-186.

Rossi FM, Sala R, Maffei L (2002) Expression of the nerve growth factor receptors TrkA and p75NTR in the visual cortex of the rat: development and regulation by the cholinergic input. J Neurosci 22:912-919.

Shi B, Stanfield BB (1996) Differential sprouting responses in axonal fiber systems in the dentate gyrus following lesions of the perforant path in WLDs mutant mice. Brain Res 740:89-101.

Shu XQ, Mendell LM (1999) Neurotrophins and hyperalgesia. Proc Natl Acad Sci USA 96:7693-7696.

Shute CCD, Lewis PR (1966) Electron microscopy of cholinergic terminals and acetylcholinesterase-containing neurones in the hippocampal formation of the rat. Z Zellforsch 69:334-343.

Smith DE, Roberts J, Gage FH, Tuszynski MH (1999) Age-associated neuronal atrophy occurs in the primate brain and is reversible by growth factor gene therapy. Proc Natl Acad Sci USA 96:10893-10898.

Sobreviela T, Clary DO, Reichardt LF, Brandabur MM, Kordower JH, Mufson EJ (1994) TrkA-immunoreactive profiles in the central nervous system: colocalization with neurons containing p75 nerve growth factor receptor, choline acetyltransferase, and serotonin. J Comp Neurol 350:587-611.
Sofroniew MV, Howe CL, Mobley WC (2001) Nerve growth factor signaling, neuroprotection, and neural repair. Annu Rev Neurosci 24:1217-1281.

Stanfield BB, Cowan WM (1982) The sprouting of septal afferents to the dentate gyrus after lesions of the entorhinal cortex in adult rats. Brain Res 232:162-170.

Steward O (1992) Signals that induce sprouting in the central nervous system: sprouting is delayed in a strain of mouse exhibiting delayed axonal degeneration. Exp Neurol 118:340-351.

Steward O, Vinsant SL (1983) The process of reinnervation in the dentate gyrus of the adult rat: a quantitative electron microscopic analysis of terminal proliferation and reactive synaptogenesis. J Comp Neurol 214:370-386.

Stroemer RP, Kent TA, Hulsebosch CE (1993) Acute increase in expression of growth associated protein GAP-43 following cortical ischemia in rat. Neurosci Lett 162:51-54.

Van der Zee CE, Fawcett J, Diamond J (1992) Antibody to NGF inhibits collateral sprouting of septohippocampal fibers following entorhinal cortex lesion in adult rats. J Comp Neurol 326:91-100.

Williams LR (1991) Hypophagia is induced by intracerebroventricular administration of nerve growth factor. Exp Neurol 113:31-37.

Xiao X, Li J, McCown TJ, Samulski RJ (1997) Gene transfer by adenoassociated virus vectors into the central nervous system. Exp Neurol 144: $113-124$. 